\title{
Leitura Deleite: o que Pensam os Professores do Ciclo Básico de Alfabetização
}

\author{
Reading Treatment: What the Professors Think of the Basic Literacy Cycle
}

\author{
Marinete Maria da Guia Campos Barros*a; Erotildes Pereira Leite ${ }^{\mathrm{a}}$; Epaminondas de Matos Magalhães ${ }^{\mathrm{ab}}$ \\ ${ }^{a}$ Instituto Federal de Mato Grosso, Programa de Pós-Graduação Stricto Sensu em Ensino. MT, Brasil. \\ bUniversidade do Estado de Mato Grosso, Programa de Pós-Graduação Stricto Sensu em Estudos Literários. MT, Brasil. \\ *E-mail: marinetecampos@hotmail.com
}

\begin{abstract}
Resumo
Esta pesquisa apresenta uma reflexão sobre a Leitura Deleite, atividade amplamente divulgada no Pacto Nacional Pela Alfabetização na Idade Certa - PNAIC. O interesse por esta temática surgiu durante a pesquisa de mestrado, em que foi observada na sala de aula a prática de Leitura Deleite. Esta entendida como uma estratégia que possibilita o despertar do prazer e reflexão sobre o que é lido, sem se preocupar com a questão formal da leitura e escrita. Nesse enfoque se buscou investigar se as docentes sabem o que é a Leitura Deleite e como a desenvolvem em sala de aula. Para tanto, foi realizada uma pesquisa de natureza qualitativa, que se desenvolveu em duas escolas públicas da rede municipal de Várzea Grande-MT. As docentes participantes responderam a um questionário, contendo cinco questões, além disso, foi realizada a observação em sala de aula. Os resultados apresentaram que as professoras conhecem substancialmente o processo de trabalhar com a Leitura Deleite, em virtude da formação do PNAIC, no entanto, a prática ainda está muito atrelada em elaborar e responder perguntas feitas pelas professoras. Acredita-se que as docentes precisam refletir mais sobre a sua própria concepção de leitura e de leitor, para possibilitar o intercâmbio com os alunos nesse processo de "conversar" com o texto, que não é ler só por ler, é ler por prazer, buscando sentido.
\end{abstract}

Palavras-chave: Leitura. Ensino. Pacto Nacional pela Alfabetização na Idade Certa- PNAIC.

\begin{abstract}
Abstrac
This research presents a reflection on Delightful Reading, an activity widely disseminated in the National Pact for Literacy at the Right Age PNAIC. The interest for this theme arose during the master's research in which the practice of Deleite Reading was observed in the classroom. This is understood as a strategy that enables the awakening of pleasure and reflection on what is read without worrying about the formal issue of reading and writing. In this approach, it was sought to investigate whether teachers know what Deleite Reading is and how it is developed in the classroom. To this end, a qualitative research was carried out in two public schools in the municipal network of Várzea Grande-MT. The participating teachers answered a questionnaire containing five questions, in addition, classroom observation was carried out. The results showed that the teachers know substantially the process of working with the Deleite Reading, due to the PNAIC formation, however, the practice is still very tied in elaborating and answering questions asked by the teachers. It is believed that teachers need to reflect more on their own conception of reading and of the reader, in order to enable exchange with students in this process of "talking" with the text which is not just reading, but reading for pleasure, seeking meaning.
\end{abstract}

Keywords: Reading. Teaching. National Pact for Literacy at the Right Age - PNAIC.

\section{Introdução}

Após os resultados das avaliações realizadas pelo Instituto Nacional de Estudos e Pesquisas Educacionais Anísio TeixeiraINEP, a partir do programa Pró-Letramento ${ }^{1}$, constatou-se que os novos índices indicavam certa melhoria nos resultados dos estudantes. Com esse indicador, projetou-se a implementação do Pacto Nacional pela Alfabetização na Idade Certa- PNAIC, visto como uma ação para o fortalecimento da alfabetização e letramento dos alunos (BRASIL, 2015).

Foi então que, em 2012, reuniram-se representantes das secretarias de sistemas públicos de ensino, do Ministério da Educação - MEC, e universidades, representantes de professores, para a elaboração e produção de documentos que explicitassem a necessidade de garantia de "direitos à educação" das crianças no Ciclo de Alfabetização, surgindo dessa forma um pacto que é assumido pelos Governos Federal, Distrito Federal, Estados e municípios, no sentido de garantir que todas as crianças estejam alfabetizadas até os oito anos de idade, ou seja, no final do terceiro ano do Ensino Fundamental- anos iniciais. Para este objetivo, o professor alfabetizador assume papel central no sentido de atingir a meta proposta pelo Programa.

Com esse compromisso, buscou-se contribuir para o

1 O Pró-Letramento foi um Programa desenvolvido pelo Ministério da Educação, em parceria com 19 universidades que integram a Rede Nacional de Formação Continuada e com a adesão de Estados e municípios. Neste programa, os educadores no exercício do magistério poderiam fazer dois tipos de formação: um curso de alfabetização e linguagem e outro de matemática. O objetivo deste Programa foi o de preparar o professor, através dos conteúdos, para enfrentar o desafio de ensinar a criança a ler e escrever, aumentando a sua autoestima e o enfrentamento ao fracasso escolar. Disponível em: http://portal.mec.gov.br/pro-letramento. 
aperfeiçoamento profissional dos professores alfabetizadores. Nesse sentido, organizou-se um conjunto integrado de ações, materiais e referências curriculares e pedagógicas disponibilizados pelo MEC, tendo como eixo principal a formação continuada de professores alfabetizadores. Assim, as ações do PNAIC se apoiaram em quatro eixos de atuação: formação continuada presencial para professores alfabetizadores e seus orientadores de estudo; materiais didáticos, obras literárias, obras de apoio pedagógico, jogos e tecnologias educacionais; avaliações sistemáticas; gestão, controle social e mobilização (BRASIL, 2015).

Com a implementação do PNAIC, houve uma preocupação muito grande com a formação continuada dos docentes e também com os materiais de apoio pedagógicos a serem disponibilizados para as escolas. Nesse contexto, não se podem negar os avanços que têm ocorrido no tratamento da leitura em sala de aula. O Programa Nacional do Livro Didático - PNLD, e o Programa Nacional Biblioteca da Escola - PNBE têm colaborado para que o livro literário entre nas escolas de todo o país, ampliando as possibilidades de ação diária pelo professor e possibilitando a inserção dos alunos no universo literário.

No entanto, o fato de existir livros na escola não significa ter alunos leitores. Para isso, é preciso contar com a mediação dos docentes nesse incentivo, pois infelizmente se encontra nas escolas um número expressivo de crianças que não tiveram em sua infância o contato com a leitura e escrita. Isso é possível de constatar ao se reportar às pesquisadoras Teberosky e Colomer (2003), os quais esclarecem que as crianças que participam de experiências de leitura compartilhada na família se mostram mais interessadas na hora de desenvolver as atividades de leitura e escrita e solicitam mais leituras de livros do que aquelas que não obtiveram esse contato. Por isso, acredita-se que o prazer nasce do ouvir as histórias narradas na infância e estas povoam a mente de prazer, alegria e mistérios.

Nesse contexto de preocupações com a qualidade do ensino da leitura, a Leitura Deleite reaparece como uma das atividades centrais proposta pelo PNAIC para o trabalho com a alfabetização, com o objetivo de oportunizar aos alunos o contato com diferentes gêneros textuais, principalmente os literários, ampliando assim o seu repertório e os incentivando ao prazer pela leitura. Consiste na leitura diária pelo professor, com a finalidade de incentivar o interesse e despertar o gosto pela leitura dos alunos. Assim é possível torná-los leitores e escritores.

Durante a realização da pesquisa de mestrado, em duas escolas da rede pública de ensino, foi possível verificar a existência de uma prática diária de Leitura Deleite nas salas de aula, pelas docentes, que a consideram como uma estratégia extremamente necessária e importante. Nesse momento, elas escolhiam um livro literário e faziam uma leitura oral para os alunos, o que acontecia geralmente no primeiro horário. Essa sistematização ocorreu durante todos os dias da observação.
A partir dessa verificação, resolveu-se enveredar pelo caminho do desconhecido e entender se as docentes tinham clareza do significado dessa estratégia. Nessa busca, foi realizado um questionário semiaberto, contendo cinco questões e também observações em sala de aula.

Nesse processo de conhecer o desconhecido, foi possível ter contato com as ideias das autoras Brandão e Rosa (2010), que propõem uma reflexão crítica sobre a importância do "diálogo" ou "conversa" sobre os textos, principalmente, ao ler os gêneros literários, enfatizando que esta ação precisa ser mais valorizada na escola. Destacam que não é ler por ler, mas buscar sentido para a leitura e acrescentam que o letramento literário implica em uma aproximação do leitor com o texto, despertando, além do prazer de ler, a fruição estética, a multiplicidade de sentidos e a ampliação do universo cultural. Nesse aspecto, as autoras sinalizam a necessidade da conversa mediada pelo professor com a obra, estabelecendo relação afetiva, estética e de sentido.

Entende-se que a Leitura Deleite pode possibilitar à criança o acesso a diferentes textos, e, em especial, os literários. Para tanto, o professor tem um papel fundamental de mediar o diálogo do aluno com os textos, no sentido de motivá-los a esse momento de prazer e fruição, sem que seja uma prática engessada de simplesmente ler o livro e cumprir uma rotina preestabelecida.

Este estudo se justifica, pois pela necessidade de se compreender o que é a Leitura Deleite e como o professor a concebe e desenvolve na sala de aula. Parte-se do pressuposto de que as docentes não foram formadas para o trabalho com a leitura e nem são leitoras, o que vai demandar uma postura reflexiva em sua prática, que a fará ressignificar alguns conceitos que constituíram a sua subjetividade.

Os resultados da pesquisa sinalizam que as docentes reconhecem a importância da Leitura Deleite, citam como sendo um momento de incentivo de despertar o interesse e o gosto do aluno pela leitura, ou seja, ler por prazer. Entretanto, durante as observações, não se verificaram ações que contribuíssem para esta finalidade, não houve "conversas" sobre os textos, e sim um monólogo entre professor e aluno, em que as perguntas eram elaboradas pelos docentes.

\section{Material e Métodos}

Nada pode ser intelectualmente problema se não tiver sido, em primeiro lugar, um problema da vida prática (MINAYO, 2016). Em consonância com a autora, este estudo buscou responder a um problema real observado durante a pesquisa, nas turmas do segundo ano do Ciclo de Alfabetização. Percebeu-se nas observações que as docentes realizam a Leitura Deleite em todas as aulas. Daí vieram alguns questionamentos: As docentes entendem o que é Leitura Deleite? Como elas a desenvolvem em sala de aula? Estas foram as questões que nortearam a pesquisa.

Assim, este estudo se ancorou ao projeto número 
98947118.20000.5165, aprovado pelo Comitê de Ética em Pesquisa-CEP da Universidade Cuiabá-UNIC/MT, em reunião realizada no dia 27 de setembro de 2018 , sob o parecer 2.922.865.

É uma pesquisa de cunho qualitativo, pois se preocupa com o universo dos significados, dos motivos, das aspirações, das crenças, dos valores e das atitudes dos seres humanos que pensam, interpretam dentro e a partir da realidade vivida (MINAYO, 2016). Além disso, esta é descritiva, em função de que se analisam os dados, a partir do resultado dos questionários e das observações.

Para conhecer as vozes das professoras a respeito da problemática supracitada, aplicou-se um questionário que, para Gil (2008), é uma técnica de investigação composta por um conjunto de questões, às quais são submetidas a pessoas com o propósito de obter informações que se deseja, a partir dos objetivos propostos. O questionário aplicado foi composto por cinco questões, duas fechadas e três abertas, que foram respondidas pelas docentes no horário de trabalho.

Paralelo à aplicação do questionário foi realizada a observação. Esta técnica é imprescindível durante a pesquisa, mas é na coleta de dados que seu papel se torna mais evidente. A observação nada mais é do que o uso dos sentidos com vistas a adquirir os conhecimentos necessários para o cotidiano. Nesta, o objeto de estudo da pesquisa é percebido diretamente sem qualquer intermediação (GIL, 2008). Por isso, a observação é extremamente importante, pois por meio dessa se tem acesso às informações adicionais sobre o problema a ser estudado, dando um conhecimento suscetível para analisar, compreender e interpretar.

A observação ocorreu no período de um mês, sendo um total de oito horas semanais para cada sala de aula. Nesse momento, foi observada a prática das docentes quanto ao direcionamento da Leitura Deleite. Para a sistematização desses dados foi utilizado o "caderno de campo", no qual foram registradas todas as informações.

Para a interpretação dos dados do questionário e da observação foi utilizado o método da análise textual discursiva, enfatizado por Moraes (2003) como sendo um processo organizado de construção de compreensão dos textos. Essa técnica de análise possibilitou a reflexão sobre as vozes das docentes em paralelo com as informações obtidas nas observações, que serão clarificadas nos resultados e discussões.

\section{Resultados e Discussão}

São descritos nesta etapa os resultados do questionário aplicado às docentes, o qual foi constituído por cinco questões. Destas, foi feita a análise de duas, que estão mais estritamente relacionadas ao objetivo da pesquisa. Além desses se têm as informações das observações realizadas em sala de aula, que também serão contrastadas com as respostas do questionário. Para esta análise, as docentes participantes serão identificadas como Margarida e Girassol.
Abaixo as respostas das docentes à pergunta: "Considera importante a utilização da Leitura Deleite em sala de aula? Por quê?" Professora Margarida: "Sim, porque desperta nos alunos a curiosidade e o prazer pela leitura". Professora Girassol: "Sim, é importante para a formação do leitor, ampliando assim o seu conhecimento".

Pelas respostas das professoras se pode perceber que elas identificam que a Leitura Deleite é de fundamental importância como potencializadora para o despertar da curiosidade, prazer e ainda na formação do leitor, ampliando assim o conhecimento dos alunos.

Isso também se verifica quando ao se reportar às ideias de Leal e Pessoa (2012), que enfatizam ser a atividade de Leitura Deleite muito importante, pois pode proporcionar instantes de leitura direcionados ao prazer. Esse tempo deve ser de prazer e reflexão sobre o que é lido, sem a preocupação sistemática com a leitura. É ler para se divertir, sentir prazer e refletir sobre a vida. No entanto, tal prática não exclui a "conversa" entre os interlocutores, pois esse tempo, além de favorecer o prazer, também contribui para a ampliação dos saberes.

Percebe-se que o discurso das docentes tem relação com alguns dos argumentos defendidos pelas autoras supracitadas, no que concerne ao prazer da leitura, entretanto elas vão muito adiante desse aspecto, em que acreditam ser a Leitura Deleite um momento para além do prazer, envolvendo uma "conversa" entre os interlocutores, que possibilita uma reflexão que amplia os saberes. Então, não é o caso de ler por ler, mas ler por prazer e conhecer o mundo.

Esse envolvimento durante a Leitura Deleite não foi observado nas salas de aula, principalmente, na turma da professora Margarida. Muitos alunos conversavam, brincavam com os materiais escolares, não estavam atentos ao enredo da história, portanto não usufruíram do contexto literário.

Segundo Brandão e Rosa (2010), ao ouvirem histórias, as crianças são mobilizadas em vários aspectos, como no envolvimento do seu corpo, suas ideias, sua linguagem, seus sentimentos, seus sentidos, sua memória e imaginação, sendo que estes não foram contemplados na turma da referida professora. Assim, percebe-se que há discrepância entre o que ela defende ser a Leitura Deleite e a prática em sala de aula. No caso, não ficou perceptível o objetivo da leitura, dificultando o engajamento dos alunos na atividade.

Acredita-se que um dos motivos pelos quais alguns alunos não se envolveram durante a Leitura Deleite tenha a ver com o não entendimento do objetivo dessa leitura, que desencadeou o não sentir prazer, o gosto de ouvir as histórias, pois não encontravam sentido nessa atividade. Nessa vertente, Cruz (2012, p.2765) esclarece:

Para que o aluno se encante pela leitura, contudo, é necessário que o próprio professor seja leitor e mostre entusiasmo pela fruição do texto. Não se está aqui fazendo uma crítica gratuita ao trabalho docente, uma vez que é sabida a falta de tempo e até mesmo de dinheiro para a dedicação de professores à leitura, mas é inegável que o aluno apreende do mestre o gosto com que o mesmo comenta e sugere leituras, o entusiasmo 
com que se refere à atividade leitora como possibilidade de lazer, fruição.

Outra possibilidade é a influência quanto às experiências de leitura pelos quais a professora passou durante a sua trajetória de vida pessoal e profissional, que não a constituiu como leitora. Diante desse contexto, defende-se que é preciso que a docente reflita quanto ao seu papel de mediadora desse processo, na perspectiva de um modelo a ser seguido pelo aluno. Em grande parte, o prazer e o desprazer, com relação à leitura têm a ver com a experiência de leitura mediada pelo professor. Se for algo prazeroso, com certeza os alunos perceberão, em sua leitura, no modo que se relaciona com os livros, na expressão, caso contrário, também sentirão. Assim, para que o contato do aluno/texto seja o menos dolorido possível, é necessário encontrar um professor leitor.

Verifica-se, então, que as professoras professam o discurso amplamente divulgado na formação do PNAIC, que enfatiza a necessidade do instante da Leitura Deleite, em sala de aula, como oportunidade de trabalhar com os diferentes gêneros textuais, pensando em despertar o prazer o gosto pela leitura e formando, assim, alunos leitores, porém não se evidenciou o discurso na prática.

No segundo questionamento foi solicitado para que as professoras descrevessem os procedimentos utilizados no momento da Leitura Deleite: a Professora Margarida aponta: "Ler o livro com antecedência, fazer leituras de diferentes gêneros e autores, ler para os alunos com entonação necessária, mostrando as ilustrações para os alunos". A Professora Girassol indica: "Seleção, antecipação, inferência e verificação, fazendo perguntas para verificar se de fato as crianças estavam atentas".

$\mathrm{Na}$ resposta da Professora Margarida, percebe-se um conhecimento elementar sobre alguns procedimentos necessários para o trabalho com a Leitura Deleite, visto muito timidamente quando se refere à escolha dos gêneros com antecedência, a leitura com entonação, socialização das ilustrações. Durante as observações, a prática mais comum da professora foi a oralização dos textos e, algumas vezes, leu as histórias com entonação e expressão. Antes de iniciar a leitura do texto, ela explorava rapidamente as ilustrações da capa, as imagens, o título do livro e indicava o nome dos autores.

No decurso da leitura do texto, percebia-se que os alunos queriam fazer um comentário, mas só era permitido ao término da leitura e, isso de forma muito elementar. O sentido maior estava para as perguntas elaboradas pela professora, que caminhavam sempre na mesma direção: "Vocês gostaram da história?" Em coro, os alunos respondiam: "Sim”. Em seguida as seguintes perguntas: "O que aconteceu nessa história? Quais são os personagens? Em que local acontece a história?”. Parecia mais um monólogo do que uma conversa sobre o texto. Essa sistematização direcionou todos os instantes observados da Leitura Deleite, durante o período de um mês, desta pesquisa. A Leitura Deleite se resumia em ler o texto, fazer perguntas com o objetivo de encontrar as informações explícitas, sendo raríssimas questões de compreensão que levariam a uma reflexão crítica. A esse respeito, as autoras Brandão e Rosa (2010) defendem que a conversa sobre o texto, além de ajudar as crianças a construírem significados e ampliarem sua compreensão, pode funcionar como uma estratégia do professor para ensinar a compreensão, algo geralmente esquecido na escola.

Com esses procedimentos se percebe que a referida professora estabelece uma prática voltada mais para a decodificação do texto, priorizando a extração das informações explícitas. Dessa forma, a "conversa" sobre o texto é limitada, pois o foco está nas perguntas elaboradas pela docente e que precisam ser respondidas pelos alunos, sem exigência de uma reflexão.

Para além dessa concepção, Cosson (2018) esclarece que ler consiste em produzir sentidos por meio do diálogo, de uma conversa. Diálogo este que se trava com o passado, enquanto experiência do outro, experiência que é compartilhada e pela qual o sujeito se insere em determinada comunidade de leitores. Logo, a leitura é um diálogo, uma conversa, pois é por meio dessa que se faz parte do mundo de leitores. Essa conversa, no entanto, deve ser planejada e, para além dessa, deve haver abertura para se ouvir, de fato, as vozes das crianças, propondo uma interação entre o leitor, o texto e autor.

Corroborando com o autor supracitado, Kleiman (2002) destaca que pesquisas recentes vêm demonstrando ser durante a interação da leitura que o leitor mais inexperiente compreende o texto: não é durante a leitura silenciosa, nem durante a leitura em voz alta, mas durante a conversa sobre aspectos relevantes do texto. Muitos aspectos que o aluno sequer percebeu durante a leitura ficam salientes nessa conversa, muitos pontos obscuros são iluminados na construção conjunta da compreensão. Não é, contudo, qualquer conversa que serve de suporte temporário para compreender o texto. Assim, para evitar que a conversa fique esvaziada, é necessário que o professor faça o planejamento. Neste instante, um dos aspectos principais a ser pensado é sobre a escolha do texto a ser lido, momento este em que se deve levar em conta os conhecimentos prévios (linguísticos, textual e de mundo), para que haja uma interação da criança com o texto.

Já a professora Girassol demonstrou, na resposta dada, conhecimento sobre as estratégias de leitura, defendidas por Solé (1998), como procedimentos de caráter elevado, que o leitor utiliza para ajudar na compreensão do texto, no entanto não explicou de que forma cada momento aconteceria em sala de aula. E, além disso, afirmou que faria perguntas para verificar se os alunos estariam atentos à leitura do texto. Subentende-se, nesta fala, a leitura como um ato de avaliação centralizada na figura do professor que, por sua vez, é aquele que sabe e vai ensinar, cabendo ao aluno ouvir e responder às perguntas propostas por ele.

Isso se concretizou ao observar as aulas, em que se verificou 
que algumas das estratégias descritas se efetivaram. Uma dessas foi com relação às perguntas relacionadas à motivação inicial, em que se propõe fazer questionamentos para que o aluno possa entrar na história. Assim, pergunta-se sobre o título, as imagens, o autor, motivando inclusive os alunos a falarem sobre algumas suposições quanto à temática a ser abordada, o significado das imagens. Entretanto, ficou por aí, ao final da leitura não se voltou às previsões realizadas, a fim de verificar se estas foram concretizadas ou foram refutadas. A docente retorna ao texto fazendo algumas perguntas de forma explícita, acreditando ser este um procedimento essencial, sem se ater a outras estratégias que estão implicitamente imbricadas. Percebe-se que a preparação para a leitura e sua execução aconteceu de forma superficial, sem considerar as estratégias por ela citadas no questionário.

A esse respeito, Solé (1998) esclarece que o trabalho com estratégias de facilitação da compreensão leitora pode ser invocado em três etapas da leitura: I) antes da leitura, momento em que o leitor é convidado a participar da leitura, sente-se capaz de fazê-lo, encontra sentido nessa, sabe o que fazer e por que fazer, conhece os objetivos que se pretende alcançar ativando os conhecimentos prévios, incentivando suas previsões e perguntas; II) durante a leitura, quando vão sendo mobilizadas várias estratégias de forma consciente e inconsciente, que auxiliarão na interpretação e compreensão do texto; e III) depois da leitura, momento de predisposição para a conversa sobre o texto, em que se pode identificar a sua ideia central, a elaboração de um resumo oral, a formulação de perguntas e respostas a partir dos textos.

Fica evidente que as estratégias não se resumem a um bloco de perguntas sem nexo, a serem elaboradas para os alunos responderem. As estratégias de leitura oferecem à criança procedimentos adequados para que desenvolvam as habilidades necessárias à compreensão. Esse ensino se faz em um movimento que envolve o antes, o durante e o depois da leitura, devendo compor um ciclo para que se possa garantir a formação de um leitor autônomo. Nessa perspectiva, as estratégias de leitura aparecem como uma possibilidade para se trabalhar com a Leitura Deleite, no sentido de buscar procedimentos adequados para a seleção de textos, o incentivo, a descoberta, a inferência, a previsão e a compreensão.

Pela consonância com as reflexões pontuadas neste texto, merece destaque a contribuição da Lerner (2002), quando indica aos professores que trabalham com a fase inicial da alfabetização que o seu trabalho é de fundamental importância, pois serve como um modelo de comportamentos a ser seguido pelo aluno. Daí que, ao ler uma história, devese criar um clima propício para desfrutá-la, propondo que as crianças se sentem em círculo para que todos possam ouvir, ver as imagens e o texto. Ler tentando criar emoção, intriga, suspense ou diversão, evitando fazer perguntas constantes durante a leitura do texto, pois pode dificultar o entendimento.

As autoras Brandão e Rosa (2010) também contribuem com a discussão formalizada, indicando que, a partir de uma análise das perguntas nas seções de compreensão de textos de livros didáticos de Língua Portuguesa, bem como daquelas indicadas por alguns autores (DELL'ISOLA, 2001; MARCUSCHI, 2008; SOLÉ, 1998), podem ser utilizadas cinco categorias de perguntas de compreensão importantes de serem levadas em conta durante a leitura e a compreensão dos textos:

a) perguntas de ativação de conhecimentos prévios: tais perguntas são formuladas, em geral, antes da leitura do texto e têm o objetivo de convidar os leitores ou ouvintes a entrarem no texto que será lido, trazendo para a situação de leitura conhecimentos que possam ser relevantes para sua compreensão;

b) perguntas de previsão sobre o texto: estas questões são muito próximas do tipo descrito acima, já que se faz previsões com base em conhecimentos prévios;

c) perguntas literais ou objetivas: são aquelas cujas respostas estão explicitamente colocadas, sendo, portanto, encontradas diretamente no texto;

d) perguntas inferenciais: são aquelas que vão além das informações explicitamente colocadas no texto, pois implicam o estabelecimento de relações por parte do leitor, ora de natureza mais simples, ora de natureza mais complexa;

e) perguntas subjetivas: são as que solicitam a opinião e/ou conhecimento do leitor e, embora tomem o texto como referência, a resposta dada não pode ser deduzida desse.

A partir das discussões propostas pelos pesquisadores se pode defender o uso das "estratégias de compreensão leitora", não como técnicas precisas, receitas infalíveis, ou habilidades específicas, mas como procedimentos que envolvem objetivos e planejamento para o trabalho com a Leitura Deleite, para além do prazer. Corroborando, Lerner (2002), Cosson (2018) e Kleiman (2002) acreditam que, para além do prazer, pode-se inserir o "diálogo" a "conversa" com o autor, texto, buscando sentido. O gosto pela leitura e o prazer dessa atividade é algo que se ensina e cabe ao professor alfabetizador direcionar esse instante de uma forma criativa, interessante e planejada. Portanto, este se delineia como um elemento chave no processo de mediação entre o livro e o leitor.

\section{Conclusão}

A realização do presente estudo potencializou uma reflexão sobre o conhecimento do professor alfabetizador acerca da Leitura Deleite e sua prática em sala de aula. Esta é uma atividade permanente, que se realiza nas escolas, a partir da sua emersão no PNAIC e serve para despertar o interesse do aluno para a leitura, a partir do contato com diferentes gêneros textuais, contribuindo para o desenvolvimento da capacidade de inferir e fazer previsões.

Ao se realizar a Leitura Deleite da mesma forma, todos os dias, sem traçar objetivos claros, sem planejamento, sem fazer deste ato um momento de prazer de "conversa" com o texto, em nada contribuirá para a formação do leitor. Pelo contrário, mostrará, por meio do exemplo, que o ler consiste em uma atividade enfadonha e sem vida, que se limita a um exercício de responder perguntas. Assim, defende-se que é preciso 
uma reflexão dos docentes sobre a sua concepção de leitura e de leitor, para possibilitar a interlocução com os alunos no processo de "conversar" com o texto, que não é ler só por ler, é ler por prazer, mas buscando sentido.

As limitações impostas pela formação inicial e profissional das docentes, que não valoram a formação leitora, a falta de um trabalho colaborativo nas escolas voltado para a leitura, a falta de bibliotecas, a falta de incentivo das famílias à leitura, a falta de políticas públicas voltadas para a formação leitora dos docentes podem impossibilitar o trabalho efetivo nas escolas com a leitura. Portanto, é preciso, com urgência, que os docentes, equipe gestora, a família, o governo e a sociedade despertem para a importância do papel que cada um desempenha na formação do leitor, que hoje ainda se limita a decodificar e não consegue interagir com o texto de forma crítica e responsiva.

Diante desse estudo, pode-se concluir que as docentes conhecem a Leitura Deleite, tendo um discurso que a consideram de extrema importância para a promoção do prazer, curiosidade, formação do leitor e ampliação do conhecimento, potencializando o acesso a uma diversidade de textos. No entanto, ao observar a sala de aula nos momentos da Leitura Deleite, presenciou-se uma prática direcionada mais para a decodificação do que para a compreensão. Assim, a "conversa" realizada durante a leitura e após não passou de um monólogo, em que as docentes perguntavam e os alunos respondiam em coro. Não houve um diálogo no sentido de discutir ideias, posições diferentes e interpretar situações para então fazer as inferências. Esse processo é muito mais complexo do que se imagina, envolve várias habilidades que precisam ser desenvolvidas e cabe ao docente mediar essa construção.

A criança precisa entender a leitura como uma atividade de construção de sentido, em que é necessário interagir com o texto. Nesse aspecto, a "conversa" é fundamental para o engajamento do aluno.

\section{Referências}

BRASIL. Pacto Nacional pela Alfabetização na Idade Certa. Interdisciplinaridade no ciclo de alfabetização. Caderno de Apresentação Brasília: MEC, SEB, 2015.

BRANDÃO, A.C.P.; ROSA, E.C.S. A leitura de textos literários na sala de aula: é conversando que a gente se entende. In: PAIVA, A.; MACIEL, F.; COSSON, R. Literatura: Ensino Fundamental. Brasília: MEC, 2010. p.69-88.

COSSON, R. Círculos de leitura e letramento literário. São Paulo: Contexto, 2018.

CRUZ, C.M. Leitura como fruição do texto no âmbito escolar e a formação de leitores. Cadernos CNLF, v.16, n.4, p.2760-2767, 2012.

GIL, A.C. Métodos e técnicas de pesquisa social. São Paulo: Atlas, 2008.

KLEIMAN, A. Oficina de leitura: teoria \& prática. São Paulo: Pontes/Unicamp, 2002.

LEAL, T.F.; PESSOA, A.C.R.G. Pacto Nacional pela Alfabetização na Idade Certa: formação do professor alfabetizador. In: BRASIL. Secretaria de Educação Básica. Diretoria de Apoio à Gestão Educacional. Formação de Professores no Pacto Nacional pela Alfabetização na Idade Certa. Brasília: MEC, 2012.

LERNER, D. Ler e escrever na escola: o real, o possível e o necessário. Porto Alegre: Artmed, 2002.

MINAYO, M.C.S. Pesquisa Social. Teoria, método e criatividade. Petrópolis: Vozes, 2016

MORAES, R. Uma tempestade de luz: a compreensão possibilitada pela análise textual discursiva publicação. Rev. Ciênc. Educ., v.9, n.2, p.191-211, 2003.

SOLÉ, I. Estratégias de leitura. Porto Alegre: Artmed, 1998.

TEBEROSKY, A.; COLOMER, T. Aprender a ler e escrever, uma proposta construtivista. Porto Alegre: Artmed, 2003. 